\title{
Gust-Load Alleviation of a Flexible Aircraft using a Disturbance Observer
}

\author{
Ryan James Caverly* \\ University of Michigan, Ann Arbor, MI, 48109, USA \\ James Richard Forbes ${ }^{\dagger}$ \\ McGill University, Montreal, Quebec, H3A 0C3, Canada \\ Brian P. Danowsky ${ }^{\ddagger}$ \\ Systems Technology, Inc., Hawthorne, CA, 90250, USA \\ Peter M. Suh ${ }^{\S}$ \\ NASA Armstrong Flight Research Center, Edwards Air Force Base, CA, 93523, USA
}

\begin{abstract}
In this paper, a disturbance observer is designed for the gust-load alleviation of a flexible high-altitude long-endurance (HALE) aircraft. A nonlinear dynamic model of a HALE vehicle is considered with a primary flight controller based on nonlinear dynamic inversion. Individual disturbance estimating filters (DEF) are designed to estimate and mitigate the effect of disturbances using sensor/actuator pairs of the aircraft. The individual DEFs are single-input single-output (SISO) disturbance observers for gust-load alleviation (DOGLAs) that are then combined together into a decoupled multi-input multi-output (D-MIMO) DOGLA. The D-MIMO DOGLA contains SISO DOGLAs dedicated to canceling out the effect of wind gusts on the body roll, pitch, and yaw rates of the aircraft, as well as on the deflection of the flexible wings. Numerical simulation results with the nonlinear flexible HALE aircraft model demonstrate that the D-MIMO DOGLA successfully mitigates the effect of wind gust loads on the aircraft in multiple flight profiles.
\end{abstract}

\section{Introduction}

High-altitude long-endurance (HALE) aircraft have garnered increased interest in recent years as they can serve several purposes, including many of the objectives of low Earth orbit (LEO) satellites while incurring a fraction of the cost to deploy. Examples of HALE applications include intelligence, surveillance, and reconnaissance (ISR), ${ }^{1}$ communications relay systems, ${ }^{2}$ and environmental and atmospheric sensing. ${ }^{3}$ Moreover, as opposed to LEO satellites, the flight path of HALE aircraft can be actively controlled. This provides the added advantage of moving the platform to different geographical areas, and to station keep, which allow HALE aircraft to serve many of the purposes of a geosynchronous satellite.

The requirements for HALE aircraft dictate that they have very high lift-to-drag ratios, and are extremely lightweight, resulting in high aspect ratios with significant structural flexibility. This results in a vehicle that is dynamically nonlinear with highly coupled rigid body and aeroelastic structural dynamics. This complicated vehicle presents a very challenging control problem. Atmospheric turbulence and gust loading can significantly impact the performance of HALE aircraft. Due to the large wingspan, this gust loading can vary spatially on the aircraft. Additionally, HALEs typically operate at very high altitudes (i.e., greater than $60,000 \mathrm{ft}$ ). Reaching the operational altitude requires the aircraft to operate safely and effectively at all altitudes in between. Some solar-powered HALE concepts require the HALE aircraft to operate at a range of altitudes; climbing to high altitude and cruising by day while gliding down to low altitude during the night. ${ }^{4}$ Because HALE aircraft must operate in a large range of altitude they experience a significant

*Ph.D. Candidate (caverly@umich.edu), Department of Aerospace Engineering, AIAA Student Member.

$\dagger$ Assistant Professor (james.richard.forbes@mcgill.ca), Department of Mechanical Engineering, AIAA Member.

¥Principal Research Engineer (bdanowsky@systemstech.com), AIAA Associate Fellow.

$\S$ Aerospace Engineer (peter.m.suh@nasa.gov), Controls Branch, AIAA Member. 


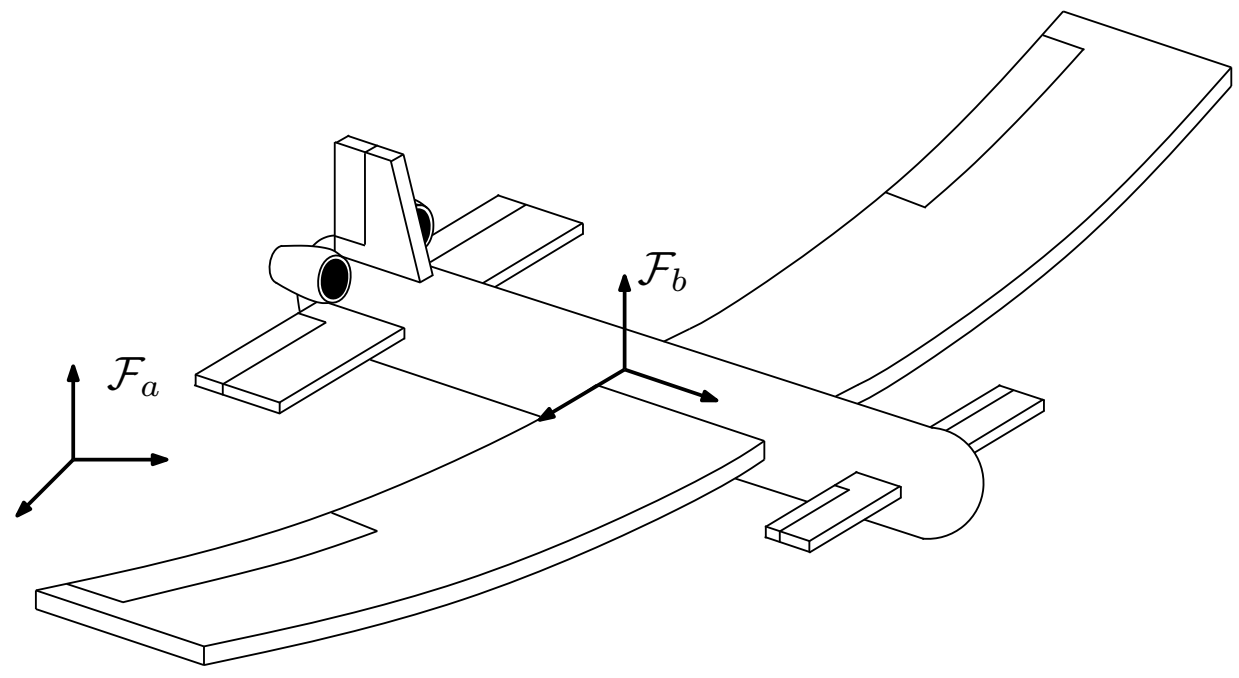

Figure 1. Visualization of a flexible aircraft with body frame $\mathcal{F}_{b}$ and inertial frame $\mathcal{F}_{a}$.

variance in atmospheric turbulence and gust loading. Due to this, resilience to turbulence and gust loading is paramount to HALE aircraft. This is reinforced by HALE test flight examples; the Aerovironment Helios mishap has been attributed to unexpected turbulence loading. ${ }^{5}$

Due to the vast importance of gust loading on these lightweight aircraft platforms, this work develops a gust load alleviation system for HALE aircraft that is based on a disturbance observer where the gust loading will be actively estimated and subsequently rejected. In the literature, disturbance observers have been implemented with the purpose of alleviating gust loads in the context of helicopters and quadrotors. ${ }^{6,7}$ There exists some research into gust-load alleviation control for HALE aircraft, ${ }^{8,9}$ which use linear quadratic Gaussian (LQG) control to mitigate the effect of gust loads, but does not explicitly estimate gust loads.

In this paper, a disturbance observer for gust load alleviation (DOGLA) is implemented in conjunction with a primary flight control (PFC) design based on nonlinear dynamic inversion (NDI). The novel contribution of this paper is the design and implementation of DOGLA on a flexible HALE aircraft. DOGLA is designed to augment a PFC and significantly improve the performance and stability of the aircraft under gust loads.

The remainder of this paper proceeds as follows. Section II presents a nonlinear dynamic model of a flexible HALE aircraft. The PFC formulation, including the NDI controller augmented with a linear controller, is included in Section III. Section IV includes the design of DOGLA. Numerical examples are presented in Section V. Concluding remarks are included in Section VI.

\section{Dynamic Model}

Consider the flexible aircraft shown in Figure 1, whose equations of motion are end $^{10,11}$

$$
\mathbf{M}\left(\mathbf{q}_{\mathrm{r}}\right) \dot{\boldsymbol{\nu}}+\mathbf{D} \dot{\mathbf{q}}+\mathbf{K q}=\mathbf{f}_{\text {non }}(\mathbf{q}, \boldsymbol{\nu}, \mathbf{u}),
$$

where $\mathbf{q}^{\top}=\left[\begin{array}{llll}\mathbf{r}_{a}^{c w^{\top}} & \mathbf{c}^{b a^{\top}} & \mathbf{q}_{\mathrm{e}}^{\top}\end{array}\right]$ are the generalized coordinates, $\boldsymbol{\nu}^{\top}=\left[\begin{array}{lll}\dot{\mathbf{r}}_{a}^{c w^{\top}} & \boldsymbol{\omega}_{b}^{b a^{\top}} & \dot{\mathbf{q}}_{\mathrm{e}}^{\top}\end{array}\right]$ are the augmented gener-

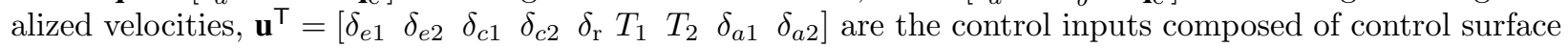
deflections and thrusts, $\mathbf{q}_{\mathrm{r}}^{\top}=\left[\mathbf{r}_{a}^{c \omega^{\top}} \mathbf{c}^{b a^{\top}}\right]$ are the rigid generalized coordinates, $\boldsymbol{\nu}_{\mathrm{r}}^{\top}=\left[\dot{\mathbf{r}}_{a}^{c w^{\top}} \boldsymbol{\omega}_{b}^{b a^{\top}}\right]$ are the rigid augmented generalized velocities, $\mathbf{r}_{a}^{c w}$ is the position of the center of mass of the aircraft relative to an unforced particle $w$ expressed in the inertial frame $\mathcal{F}_{a}, \mathbf{c}^{b a}$ is a column matrix that contains the nine entries of the direction cosine matrix (DCM) that describes the attitude of the aircraft relative to $\mathcal{F}_{a}, \mathbf{q}_{\mathrm{e}}$ are the elastic coordinates used to describe the elastic deformation of the aircraft, $\boldsymbol{\omega}_{b}^{b a}$ is the angular velocity of the aircraft relative to $\mathcal{F}_{a}$ expressed in the body frame $\mathcal{F}_{b}, \delta_{e 1}$ and $\delta_{e 2}$ are the control surface deflections of the right and left elevators, respectively, $\delta_{c 1}$ and $\delta_{c 2}$ are the control surface deflections of the right and left canards, respectively, $\delta_{\mathrm{r}}$ is the control surface deflection of the rudder, $T_{1}$ and $T_{2}$ are the thrusts produced 
by the right and left engines located on the aircraft tail, respectively, $\delta_{a 1}$ and $\delta_{a 2}$ are the control surface deflections of the right and left ailerons, respectively, $\mathbf{M}\left(\mathbf{q}_{\mathrm{r}}\right)=\mathbf{M}^{\top}\left(\mathbf{q}_{\mathrm{r}}\right)>0$ is the mass matrix, $\mathbf{D}=\mathbf{D}^{\top} \geq 0$ is the damping matrix, $\mathbf{K}=\mathbf{K}^{\boldsymbol{\top}} \geq 0$ is the stiffness matrix, and $\mathbf{f}_{\text {non }}(\mathbf{q}, \boldsymbol{\nu}, \mathbf{u})$ is a column matrix of nonlinear terms. The DCM that describes the attitude of the aircraft relative to $\mathcal{F}_{a}$ is given by $\mathbf{C}_{b a}$, and satisfies $\mathbf{C}_{b a} \in \mathbb{R}^{3 \times 3}, \mathbf{C}_{b a} \mathbf{C}_{b a}^{\top}=\mathbf{1}$, and $\operatorname{det}\left(\mathbf{C}_{b a}\right)=+1$. The HALE aircraft considered includes a (canard) forward horizontal stabilizer with control surfaces to provide an additional "rigid" control input. Due to the extreme flexibility of the wings, changes in wing loads caused by deflection of the ailerons are not directly transmitted to the fuselage, and as a result, are not very effective for attitude control of the aircraft. For this reason, the rigid canard control surfaces are primarily used for roll control. The control input $\mathbf{u}$ is partitioned into the

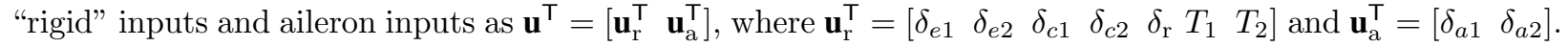

The equation of motion in (1) can be expanded as

$$
\begin{aligned}
& \mathbf{M}_{\mathrm{rr}}\left(\mathbf{q}_{\mathrm{r}}\right) \dot{\boldsymbol{\nu}}_{\mathrm{r}}+\mathbf{M}_{\mathrm{re}}\left(\mathbf{q}_{\mathrm{r}}\right) \ddot{\mathbf{q}}_{\mathrm{e}}=\mathbf{f}_{\mathrm{non}, \mathrm{r}}(\mathbf{q}, \boldsymbol{\nu}, \mathbf{u}), \\
& \mathbf{M}_{\mathrm{re}}^{\top}\left(\mathbf{q}_{\mathrm{r}}\right) \dot{\boldsymbol{\nu}}_{\mathrm{r}}+\mathbf{M}_{\mathrm{ee}} \ddot{\mathbf{q}}_{\mathrm{e}}+\mathbf{D}_{\mathrm{ee}} \dot{\mathbf{q}}_{\mathrm{e}}+\mathbf{K}_{\mathrm{ee}} \mathbf{q}_{\mathrm{e}}=\mathbf{f}_{\mathrm{non}, \mathrm{e}}(\mathbf{q}, \boldsymbol{\nu}, \mathbf{u}),
\end{aligned}
$$

where

$$
\mathbf{M}\left(\mathbf{q}_{\mathrm{r}}\right)=\left[\begin{array}{cc}
\mathbf{M}_{\mathrm{rr}}\left(\mathbf{q}_{\mathrm{r}}\right) & \mathbf{M}_{\mathrm{re}}\left(\mathbf{q}_{\mathrm{r}}\right) \\
\mathbf{M}_{\mathrm{re}}^{\top}\left(\mathbf{q}_{\mathrm{r}}\right) & \mathbf{M}_{\mathrm{ee}}
\end{array}\right], \quad \mathbf{D}=\left[\begin{array}{cc}
\mathbf{0} & \mathbf{0} \\
\mathbf{0} & \mathbf{D}_{\mathrm{ee}}
\end{array}\right], \quad \mathbf{K}=\left[\begin{array}{cc}
\mathbf{0} & \mathbf{0} \\
\mathbf{0} & \mathbf{K}_{\mathrm{ee}}
\end{array}\right], \quad \mathbf{f}_{\mathrm{non}}(\mathbf{q}, \boldsymbol{\nu}, \mathbf{u})=\left[\begin{array}{c}
\mathbf{f}_{\mathrm{non}, \mathrm{r}}(\mathbf{q}, \boldsymbol{\nu}, \mathbf{u}) \\
\mathbf{f}_{\mathrm{non}, \mathrm{e}}(\mathbf{q}, \boldsymbol{\nu}, \mathbf{u})
\end{array}\right],
$$

$\mathbf{M}_{\mathrm{rr}}\left(\mathbf{q}_{\mathrm{r}}\right)=\mathbf{M}_{\mathrm{rr}}^{\top}\left(\mathbf{q}_{\mathrm{r}}\right)>0, \mathbf{M}_{\mathrm{ee}}=\mathbf{M}_{\mathrm{ee}}^{\top}>0, \mathbf{D}_{\mathrm{ee}}=\mathbf{D}_{\mathrm{ee}}^{\top} \geq 0$, and $\mathbf{K}_{\mathrm{ee}}=\mathbf{K}_{\mathrm{ee}}^{\top} \geq 0$.

From (2) it can be shown that the equation of motion of the rigid aircraft with "rigid" control inputs is

$$
\mathbf{M}_{\mathrm{rr}}\left(\mathbf{q}_{\mathrm{r}}\right) \dot{\boldsymbol{\nu}}_{\mathrm{r}}=\mathbf{f}_{\text {non }, \mathrm{r}}\left(\mathbf{q}_{\mathrm{r}}, \boldsymbol{\nu}_{\mathrm{r}}, \mathbf{u}_{\mathrm{r}}\right) .
$$

Assuming small control surface deflections, the nonlinear term in (4) can be approximated as

$$
\mathbf{f}_{\text {non }, \mathrm{r}}\left(\mathbf{q}, \boldsymbol{\nu}, \mathbf{u}_{\mathrm{r}}\right) \approx \overline{\mathbf{f}}_{\text {non }, \mathrm{r}}(\mathbf{q}, \boldsymbol{\nu})+\hat{\mathbf{B}}_{\mathrm{r}}(\mathbf{q}, \boldsymbol{\nu}) \mathbf{u}_{\mathrm{r}} .
$$

This approximation relies on the fact that the nonlinear terms involving the control input $\mathbf{u}_{\mathrm{r}}$ come in the form of $\delta^{2}$, where $\delta$ are the individual control surface deflections. Terms of the form $\delta^{2}$ will be negligible compared to $\delta$ for small control surface deflections. Implementing this approximation, (4) becomes

$$
\mathbf{M}_{\mathrm{rr}}\left(\mathbf{q}_{\mathrm{r}}\right) \dot{\boldsymbol{\nu}}_{\mathrm{r}} \approx \overline{\mathbf{f}}_{\text {non,r }}\left(\mathbf{q}_{\mathrm{r}}, \boldsymbol{\nu}_{\mathrm{r}}\right)+\hat{\mathbf{B}}_{\mathrm{r}}\left(\mathbf{q}_{\mathrm{r}}, \boldsymbol{\nu}_{\mathrm{r}}\right) \mathbf{u}_{\mathrm{r}} .
$$

Equation (6) can also be written as

$$
\dot{\nu}_{\mathrm{r}} \approx \mathbf{f}_{\mathrm{r}}\left(\mathbf{q}_{\mathrm{r}}, \boldsymbol{\nu}_{\mathrm{r}}\right)+\mathbf{G}_{\mathrm{r}}\left(\mathbf{q}_{\mathrm{r}}, \boldsymbol{\nu}_{\mathrm{r}}\right) \mathbf{u}_{\mathrm{r}},
$$

where $\mathbf{f}_{\mathrm{r}}\left(\mathbf{q}_{\mathrm{r}}, \boldsymbol{\nu}_{\mathrm{r}}\right)=\mathbf{M}_{\mathrm{rr}}^{-1}\left(\mathbf{q}_{\mathrm{r}}\right) \overline{\mathbf{f}}_{\text {non, } \mathrm{r}}\left(\mathbf{q}_{\mathrm{r}}, \boldsymbol{\nu}_{\mathrm{r}}\right)$ and $\mathbf{G}_{\mathrm{r}}\left(\mathbf{q}_{\mathrm{r}}, \boldsymbol{\nu}_{\mathrm{r}}\right)=\mathbf{M}_{\mathrm{rr}}^{-1}\left(\mathbf{q}_{\mathrm{r}}\right) \hat{\mathbf{B}}_{\mathrm{r}}\left(\mathbf{q}_{\mathrm{r}}, \boldsymbol{\nu}_{\mathrm{r}}\right)$. The first-order form of (7) is convenient in determining the NDI control input of the PFC, as presented in Section III.

\section{Control Formulation}

The PFC uses NDI and is augmented with a linear proportional-integral-derivative (PID) controller to track a desired aircraft attitude, translational velocity, and angular velocity.

\section{A. Nonlinear Dynamic Inversion}

NDI is a nonlinear control technique that is equivalent to input-output feedback linearization. ${ }^{12,13}$ NDI control involves canceling out the open-loop system's nonlinear equations of motion and augmenting the closed-loop system with an additional controller, which may be linear, to provide additional robustness to uncertainties and improve performance. An advantage of NDI over other popular control techniques for nonlinear systems, such as gain-scheduled control, is that no linearization of the aircraft is needed.

Rigid NDI ${ }^{14,15}$ is performed on the rigid equations of motion of (7) using

$$
\mathbf{u}_{\mathrm{PFC}}=\mathbf{G}_{\mathrm{r}}^{-1}\left(\mathbf{q}_{\mathrm{r}}, \boldsymbol{\nu}_{\mathrm{r}}\right)\left(\mathbf{v}-\mathbf{f}_{\mathrm{r}}\left(\mathbf{q}_{\mathrm{r}}, \boldsymbol{\nu}_{\mathrm{r}}\right)\right),
$$




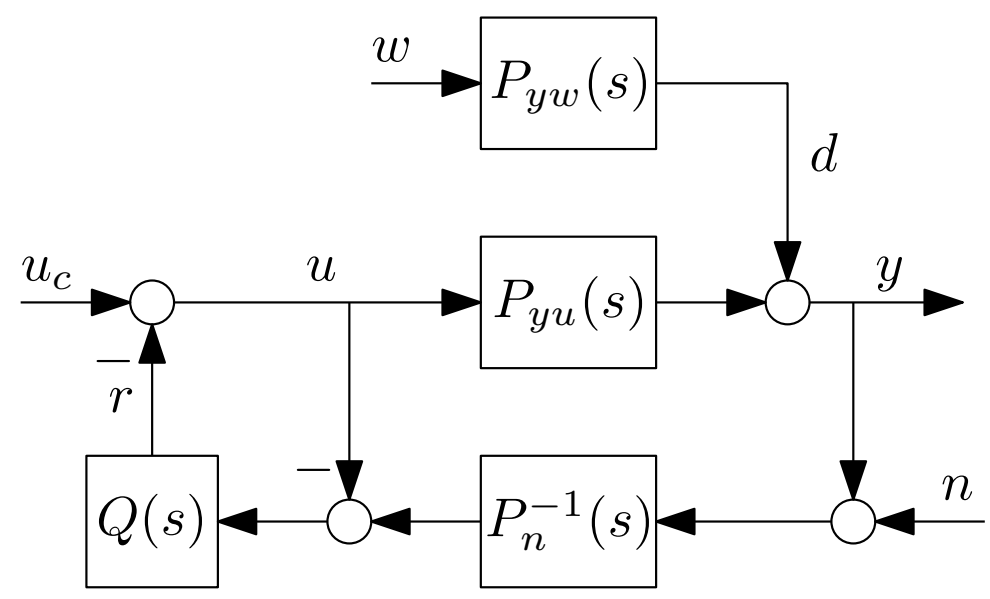

Figure 2. Block diagram of the DEF disturbance observer architecture, adapted from Ref. 18.

which yields the closed-loop system $\dot{\boldsymbol{\nu}}_{\mathrm{r}} \approx \mathbf{v}$, where $\mathbf{v}$ is the output of a linear controller. The PFC input can also expressed as $\mathbf{u}_{\mathrm{PFC}}=\mathbf{u}_{\mathrm{NDI}}+\mathbf{u}_{\mathrm{PID}}$, where $\mathbf{u}_{\mathrm{NDI}}=-\mathbf{G}_{\mathrm{r}}^{-1}\left(\mathbf{q}_{\mathrm{r}}, \boldsymbol{\nu}_{\mathrm{r}}\right) \mathbf{f}_{\mathrm{r}}\left(\mathbf{q}_{\mathrm{r}}, \boldsymbol{\nu}_{\mathrm{r}}\right)$ and $\mathbf{u}_{\mathrm{PID}}=\mathbf{G}_{\mathrm{r}}^{-1}\left(\mathbf{q}_{\mathrm{r}}, \boldsymbol{\nu}_{\mathrm{r}}\right) \mathbf{v}$.

A preliminary study on the inclusion of the flexible equations of motion in the dynamic inversion process is found in Ref. 16. The work of Ref. 16 only considers the use of NDI for the purposes of attitude control and forward speed control. Although this work seems promising for use with flexible aircraft, only NDI of the rigid equations of motion is considered in this paper for simplicity.

\section{B. Linear Controller}

The NDI control law in (8) relies on the following linear controller defined $\operatorname{as~}^{\top}=\left[\begin{array}{ll}\mathbf{v}_{\mathrm{r}}^{\top} & \mathbf{v}_{\omega}^{\top}\end{array}\right]$,

$$
\begin{gathered}
\mathbf{v}_{\mathrm{r}}=-\mathbf{K}_{\mathrm{p}, \mathrm{r}}\left(\dot{\mathbf{r}}_{a}^{c w}-\dot{\mathbf{r}}_{a}^{c w, d}\right)-\mathbf{K}_{\mathrm{i}, \mathrm{r}} \int_{0}^{t}\left(\dot{\mathbf{r}}_{a}^{c w}-\dot{\mathbf{r}}_{a}^{c w, d}\right) \mathrm{d} \tau \\
\mathbf{v}_{\omega}=\mathbf{K}_{\mathrm{p}, \omega}\left(\mathbf{C}_{b d}-\mathbf{C}_{b d}^{\top}\right)^{\vee}-\mathbf{K}_{\mathrm{d}, \omega}\left(\boldsymbol{\omega}_{b}^{b a}-\boldsymbol{\omega}_{b}^{b a, d}\right)+\mathbf{K}_{\mathrm{i}, \omega} \int_{0}^{t}\left(\left(\mathbf{C}_{b d}-\mathbf{C}_{b d}^{\top}\right)^{\vee}-k\left(\boldsymbol{\omega}_{b}^{b a}-\boldsymbol{\omega}_{b}^{b a, d}\right)\right) \mathrm{d} \tau,
\end{gathered}
$$

where $\mathbf{K}_{\mathrm{p}, \mathrm{r}}=\operatorname{diag}\left\{k_{\mathrm{p}, \mathrm{r} 1}, k_{\mathrm{p}, \mathrm{r} 2}, k_{\mathrm{p}, \mathrm{r} 3}\right\}, \mathbf{K}_{\mathrm{i}, \mathrm{r}}=\operatorname{diag}\left\{k_{\mathrm{i}, \mathrm{r} 1}, k_{\mathrm{i}, \mathrm{r} 2}, k_{\mathrm{i}, \mathrm{r} 3}\right\}, \mathbf{K}_{\mathrm{p}, \omega}=\operatorname{diag}\left\{k_{\mathrm{p}, \omega 1}, k_{\mathrm{p}, \omega 2}, k_{\mathrm{p}, \omega 3}\right\}, \mathbf{K}_{\mathrm{d}, \omega}=$ $\operatorname{diag}\left\{k_{\mathrm{d}, \omega 1}, k_{\mathrm{d}, \omega 2}, k_{\mathrm{d}, \omega 3}\right\}, \mathbf{K}_{\mathrm{i}, \omega}=\operatorname{diag}\left\{k_{\mathrm{i}, \omega 1}, k_{\mathrm{i}, \omega 2}, k_{\mathrm{i}, \omega 3}\right\}, k>0, k_{j, r l}>0$ for $j=\mathrm{p}, \mathrm{d}, \mathrm{i}$ and $l=1,2,3, k_{j, \omega l}>0$ for $j=\mathrm{p}, \mathrm{d}$, i and $l=1,2,3, \dot{\mathbf{r}}_{a}^{c w, d}$ is the desired translational velocity of the aircraft center of mass relative to an unforced particle $w$ expressed in $\mathcal{F}_{a}, \mathbf{C}_{b d}=\mathbf{C}_{b a} \mathbf{C}_{d a}^{\top}$ is the DCM describing the attitude error, $\mathbf{C}_{d a}$ is the DCM describing the desired aircraft attitude, and $\boldsymbol{\omega}_{b}^{b a, d}$ is the desired angular velocity relative to $\mathcal{F}_{a}$ expressed in $\mathcal{F}_{b}$. The uncross operator, $(\cdot)^{\vee}: \mathbb{R}^{n \times n} \rightarrow \mathbb{R}^{n}$, is defined as

$$
\mathbf{A}=-\mathbf{A}^{\top}=\left[\begin{array}{ccc}
0 & -a_{3} & a_{2} \\
a_{3} & 0 & -a_{1} \\
-a_{2} & a_{1} & 0
\end{array}\right]
$$

where $\mathbf{A}^{\mathbf{v}}=\left[\begin{array}{lll}a_{1} & a_{2} & a_{3}\end{array}\right]^{\top}$. Notice that the control law of (10) uses the DCM directly, rather than using an Euler angle or quaternion parametrization. This avoids the kinematic singularities associated with Euler angles and the unwinding of quaternions, leading to an attitude control law that is well-defined globally. ${ }^{17}$

\section{Disturbance Observer}

\section{A. DEF Design Procedure}

A DEF design procedure is chosen to synthesize DOGLA, which is described in detail in Ref. 18. The basic concept employed in designing the DEF involves the use of the inverse nominal plant model, $P_{n}^{-1}$, to estimate 

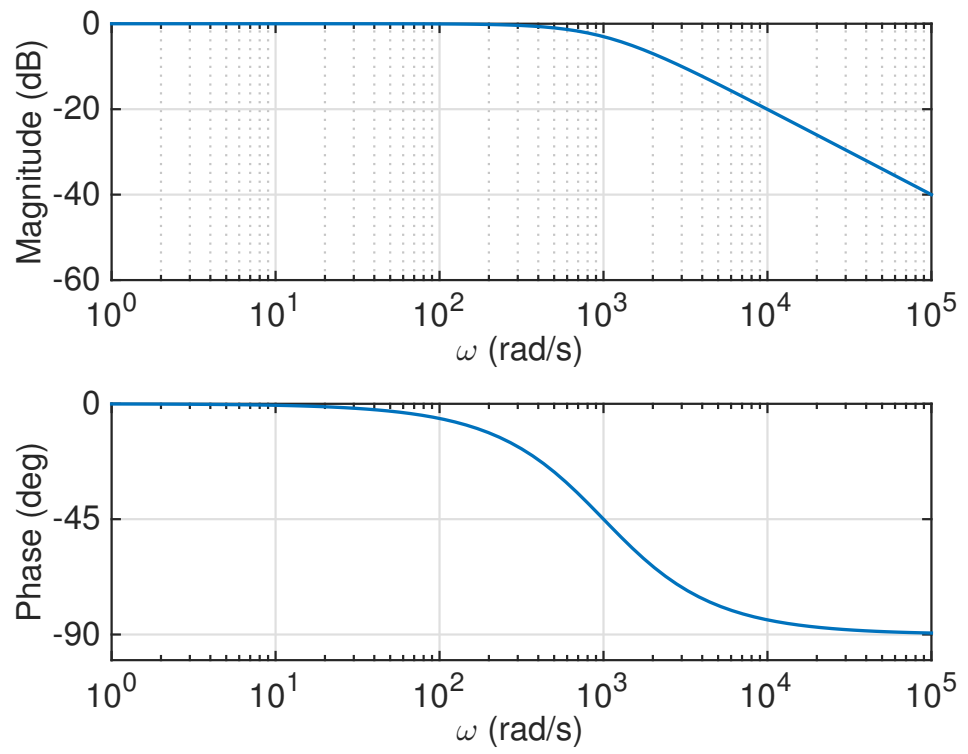

Figure 3. Bode plot of $Q(s)$ from (17) with $\omega_{\mathbf{f}}=1000 \mathrm{rad} / \mathrm{s}$.

the input to the plant based on a perturbed measurement. The true plant input is subtracted from this to obtain the estimated effect of the disturbance on the plant. This signal is then passed through a filter $Q(s)$ before being fed back to mitigate the effect of the disturbance on the plant. A block diagram illustrating the DEF architecture is shown in Figure 2. Note that the use of the inverse of the nominal plant model can lead to an unstable disturbance observer if the nominal plant model contains nonminimum phase zeros, but fortunately, in this paper the nominal plant models used are minimum phase.

The closed-loop transfer functions from the outer-loop controller, disturbance, and noise to the output $y$ are given by

$$
\begin{aligned}
H_{y u_{c}}(s) & =\frac{P_{y u}(s) P_{n}(s)}{Q(s)\left(P_{y u}(s)-P_{n}(s)\right)+P_{n}(s)}, \\
H_{y d}(s) & =\frac{P_{n}(s)(1-Q(s))}{Q(s)\left(P_{y u}(s)-P_{n}(s)\right)+P_{n}(s)}, \\
H_{y n}(s) & =\frac{-P_{y u}(s) Q(s)}{Q(s)\left(P_{y u}(s)-P_{n}(s)\right)+P_{n}(s)} .
\end{aligned}
$$

If the nominal plant model in the disturbance observer is exactly equal to the plant (i.e., $P_{n}(s)=P_{y u}(s)$ ), the equations of (11), (12), and (13) simplify to

$$
\begin{aligned}
H_{y u_{c}}(s) & =P_{y u}(s), \\
H_{y d}(s) & =1-Q(s), \\
H_{y n}(s) & =-Q(s) .
\end{aligned}
$$

The form of $H_{y d}(s)$ in (15) suggests that $Q(s)$ should be very close to 1 to ensure that disturbances are not amplified by the closed-loop system. However, the form of $H_{y n}(s)$ in (16) suggests that $Q(s)$ should be as small as possible so as to not amplify measurement noise. These competing requirements are quite common when attempting to mitigate the effect of disturbances and measurement noise in a closed-loop system. Fortunately, disturbances acting on the system are often within a frequency band that is different than the frequency band of the measurement noise, which allows for the conflicting requirements on $Q(s)$ to be satisfied within the appropriate frequency bands. Typically, disturbances are present at relatively low frequencies and measurement noise is found a high frequencies. For this reason, it is desired to design $Q(s)$ 
Table 1. Sensor/Actuator pairs used in SISO DOGLA design.

\begin{tabular}{lcc}
\hline SISO DOGLA & Sensor Measurement & Actuator \\
\hline \hline left wingtip & outboard left wing accelerometer & left wing aileron \\
right wingtip & outboard right wing accelerometer & right wing aileron \\
fuselage pitch & body pitch rate & collective elevators \\
fuselage roll & body roll rate & differential canards \\
fuselage yaw & body yaw rate & rudder \\
\hline
\end{tabular}

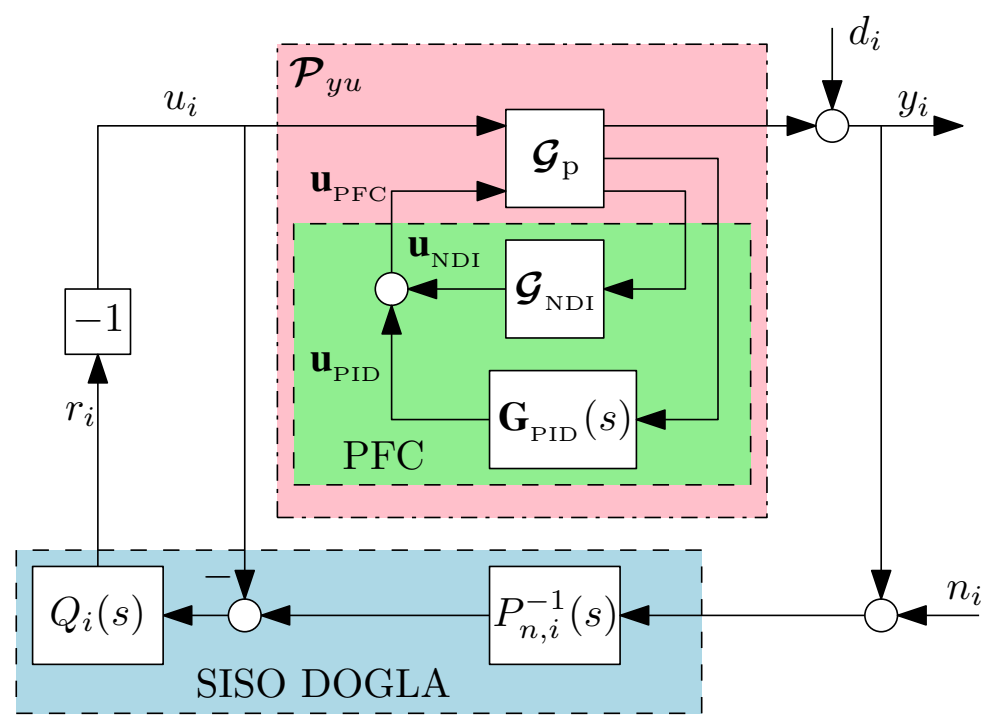

Figure 4. Block diagram of a SISO DOGLA with the PFC. Note that the operator $\mathcal{P}_{y u}$ represents the nonlinear plant, $\mathcal{G}_{\mathrm{NDI}}$ represents the NDI controller, and $\mathbf{G}_{\mathrm{PID}}$ represents the PID controller. The signals and systems with subscripts $i$ refer to the $i^{\text {th }}$ SISO DOGLA.

to be a low-pass filter. A low-pass filter can be designed to have unity gain at low frequencies, satisfying the requirement of $Q(s) \approx 1$, and roll off at high frequencies so that $Q(s) \approx 0$. In particular, the first-order low-pass filter

$$
Q(s)=\frac{\omega_{\mathrm{f}}}{s+\omega_{\mathrm{f}}}
$$

is considered in this paper. The cut-off frequency of the low-pass filter in $(17)$ is $\omega_{\mathrm{f}}$, which signifies the frequency at which the gain of $Q(s)$ begins to roll off. The Bode plot of $Q(s)$ with $\omega_{\mathrm{f}}=1000 \mathrm{rad} / \mathrm{s}$ is given in Figure 3.

The output of the DEF is given by

$$
r(s)=\left[Q(s)-Q(s) P_{n}^{-1}(s)\right]\left[\begin{array}{c}
u(s) \\
y(s)+n(s)
\end{array}\right] .
$$

Knowing that $u(s)=u_{c}(s)-r(s)$ and substituting in (18) yields

$$
\begin{aligned}
u(s) & =u_{c}(s)-r(s), \\
u(s) & =u_{c}(s)+Q(s) u(s)-Q(s) P_{n}^{-1}(s)(y(s)+n(s)), \\
(1-Q(s)) u(s) & =u_{c}(s)-Q(s) P_{n}^{-1}(s)(y(s)+n(s)), \\
u(s) & =(1-Q(s))^{-1}\left(u_{c}(s)-Q(s) P_{n}^{-1}(s)(y(s)+n(s))\right) .
\end{aligned}
$$

Assuming $u_{c}(s)=0,(22)$ can be rewritten as

$$
u(s)=-\frac{Q(s)}{P_{n}(s)(1-Q(s))}(y(s)+n(s)) .
$$




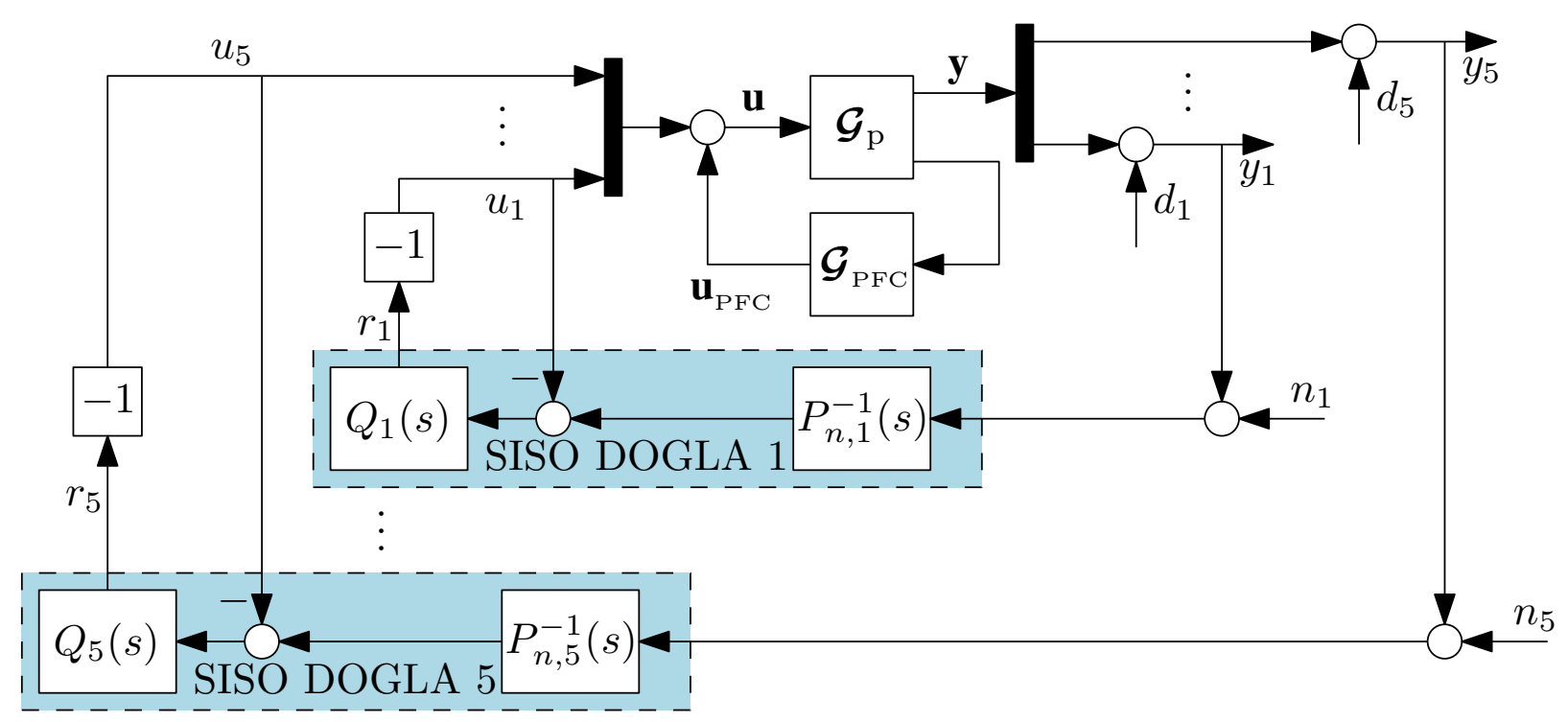

Figure 5. Block diagram of D-MIMO DOGLA with the PFC.

From (23) it can be shown that the poles of the DEF are the roots of the polynomial given by

$$
n_{P}(s)\left(d_{Q}(s)-n_{Q}(s)\right)=0,
$$

where $P_{n}(s)=n_{P}(s) / d_{P}(s)$ and $Q(s)=n_{Q}(s) / d_{Q}(s)$. It is quite important that the DEF be at least Lyapunov stable to ensure closed-loop stability, especially when $P_{n}(s)$ does not exactly equal $P_{y u}(s)$, which is always the case in practice. Using the choice of $Q(s)$ in (17), the polynomial in (24) becomes $n_{P}(s) s=0$, with roots at $s=0$ and at the zeros of $P_{n}(s)$. Therefore, the DEF is Lyapunov stable only if $P_{n}(s)$ is minimum phase. Based on the internal model principle, ${ }^{19}$ the pole of the DEF at $s=0$ allows for the closed-loop system to perfectly reject constant disturbances.

\section{B. Linearization of Nonlinear Dynamic Model}

A linear model of the HALE aircraft is needed to synthesize the DEF. The work of Ref. 18 assumes that the DEF is to be designed as an inner loop to an outer loop control system, but in this paper the DEF is designed as an outer loop to the closed-loop system with PFC. This is done to ensure that the plant model used in the DEF design is asymptotically stable, which otherwise may not be the case for a statically unstable aircraft.

A linearization of the nonlinear flexible HALE aircraft model with PFC is performed about a desired operating point, defined by a desired airspeed, angle of attack, and attitude. The linearization is performed by numerically solving for the aircraft trim inputs and finite differencing the nonlinear HALE equations of motion in (1). The linearized aircraft has 26 states, which consist of the entries of the DCM that describes the attitude of the aircraft, the inertial position of the center of mass, the inertial velocities of the center of mass, the body-frame angular velocity of the aircraft, flexible modal states, and flexible modal state rates. The nine control inputs defined in Section II are inputs to the linearized model, in addition to 36 wind gust inputs that can be applied in multiple directions and at various locations on the aircraft. The outputs of the linearized model, which represent the measurements available in synthesizing individual SISO DOGLAs, consist of the body-frame velocity of the center of mass, body-frame angular velocity, roll, pitch, and yaw angles, inertial positions of the center of mass, acceleration of the flexible wings at multiple locations.

\section{Discussion on Nonminimum Phase Zeros}

As mentioned in Section IV-A, it is imperative that the zeros of $P_{n}(s)$ be minimum phase. The relevant plant transfer functions resulting from the linearization of Section IV-B are minimum phase, which leads to Lyapunov stable SISO DOGLAs. In cases where nonminimum phase plant models arise, there are a few options to ensure that the SISO DOGLAs are Lyapunov stable. 
Table 2. Main specifications of HALE aircraft used in the simulation.

\begin{tabular}{lc}
\hline Property & Value \\
\hline \hline aircraft wingspan & $16.5 \mathrm{~m}$ \\
aircraft length & $6 \mathrm{~m}$ \\
aircraft mass & $7 \mathrm{~kg}$ \\
wing airfoil & NACA 0012 \\
wing chord length & $0.5 \mathrm{~m}$ \\
wing aspect ratio & 33 \\
wing thickness & $0.02 \mathrm{~m}$ \\
wing elastic modulus & $80 \mathrm{GPa}$ \\
rear horizontal stabilizer airfoil & $\mathrm{NACA} 0012$ \\
rear horizontal stabilizer chord length & $0.5 \mathrm{~m}$ \\
rear horizontal stabilizer span & $4.5 \mathrm{~m}$ \\
vertical stabilizer airfoil & $\mathrm{NACA} 0012$ \\
vertical stabilizer chord length & $0.75 \mathrm{~m}$ \\
vertical stabilizer span & $0.3 \mathrm{~m}$ \\
forward (canard) horizontal stabilizer airfoil & NACA 0012 \\
forward (canard) horizontal stabilizer chord length & $0.5 \mathrm{~m}$ \\
forward (canard) horizontal stabilizer span & $4.5 \mathrm{~m}$ \\
\hline
\end{tabular}

The first option is to perform "zero shaping," where the zeros of the transfer function are modified to be minimum phase. This can be accomplished using a "squaring-up" procedure, ${ }^{20-23}$ implementing a parallel feedforward controller to place the zeros of the system, ${ }^{24,25}$ or designing the closed-loop system to have nonzero minimum gain. ${ }^{26,27}$

The second option is to simply remove the nonminimum phase zeros of the transfer function. The system $P_{n}(s)$ does not need to be an exact representation of the plant, and can therefore be manually modified to be minimum phase.

A third option is to select different sensors/actuators or combinations of sensors/actuators to obtain minimum phase transfer functions. For example, differential canards are used as inputs for the fuselage roll DOGLA, but instead differential elevators, or even differential elevators and canards, could be used for the same purpose. In cases with a nonminimum phase transfer function, it is possible one of these other sensor/actuator combinations will lead to a minimum phase transfer function.

\section{Individual SISO and Complete D-MIMO DOGLAs}

Individual SISO DOGLAs are formulated using the DEF design procedure. The chosen sensor/actuator pairs are listed in Table 1. Three SISO DOGLAs are used for disturbance rejection in the three body axes of the fuselage and two more are used for disturbance rejection and vibration suppression of the flexible wings. Notice that the ailerons are used in the left and right wingtip DOGLAs, but are not used in the PFC. A block diagram of SISO DOGLA with the PFC is shown in Figure 4.

The D-MIMO DOGLA is synthesized by combining the five individual SISO DOGLAs and implementing them simultaneously. When implemented with the PFC, the control inputs of the D-MIMO DOGLA are added on top of the PFC control inputs. Figure 5 includes a block diagram of D-MIMO DOGLA composed of five individual SISO DOGLAs with the PFC.

\section{Numerical Examples}

Numerical simulations are performed with the nonlinear flexible HALE aircraft model described in Section II. The main specifications of the HALE aircraft used in the following numerical results are given in Table 2. Results with two flight profiles are presented in this section. The first set of simulation results are performed with the aircraft at steady level flight conditions, while the second set of results are with the aircraft in an ascent phase. Severe wind gust loads generated by a Dryden gust filter are applied at twelve 

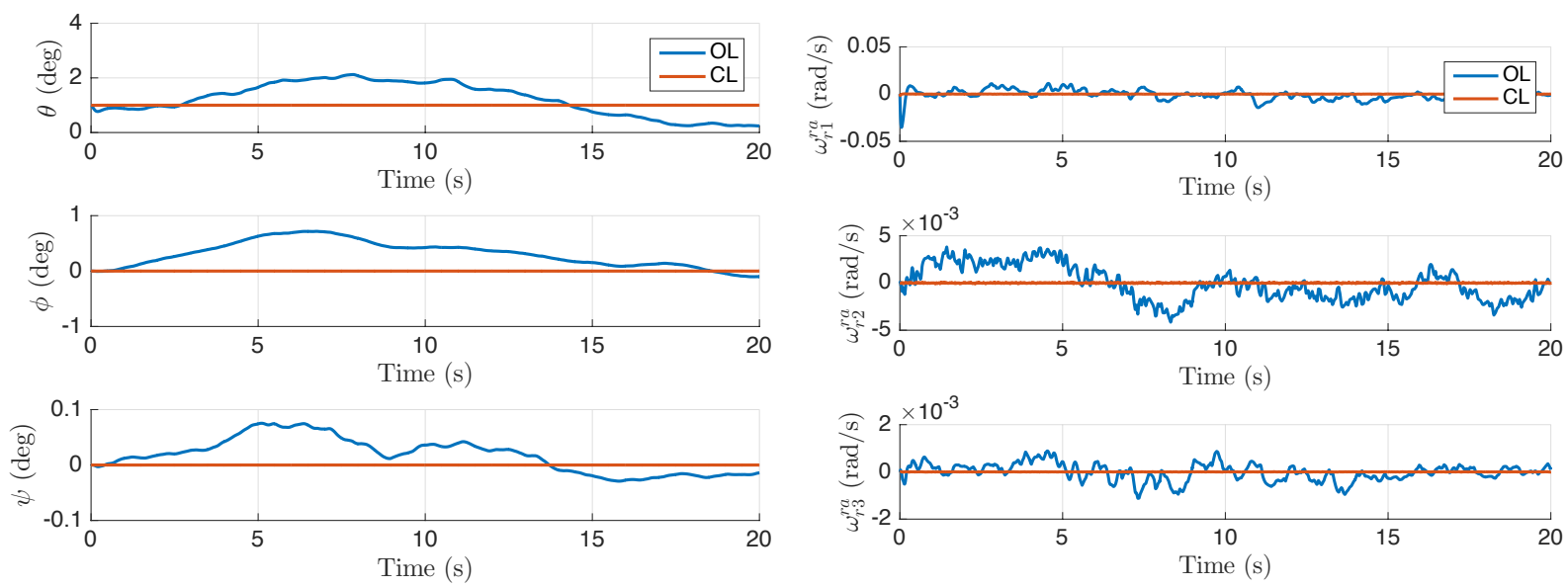

(a)

(b)
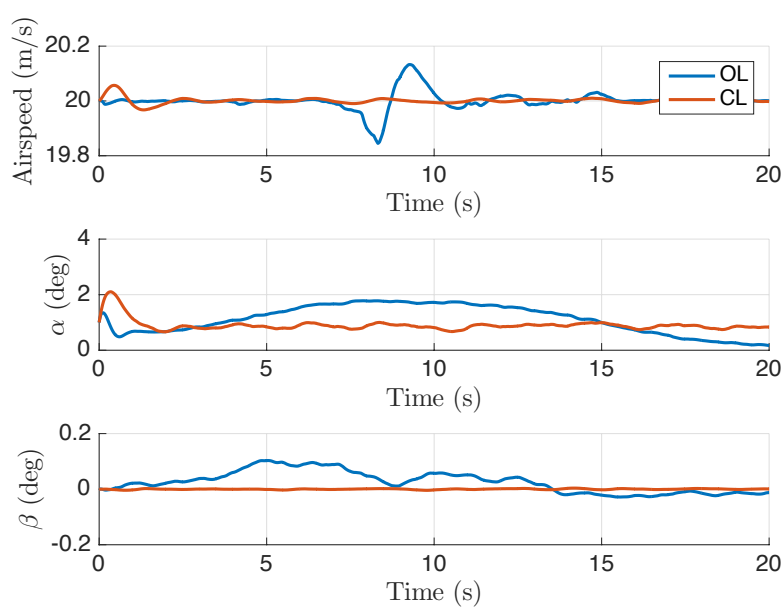

(c)
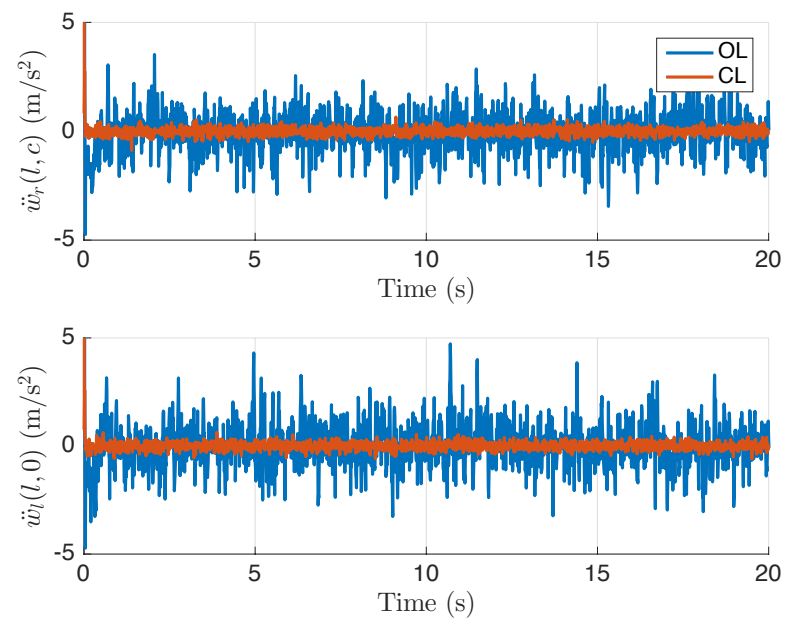

(d)
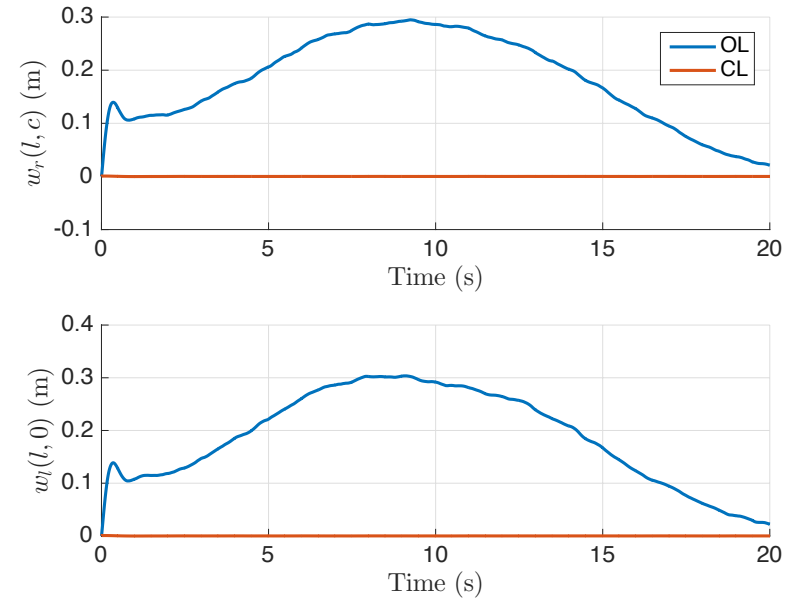

(e)

Figure 6. Open-loop (OL) and closed-loop (CL) responses with Dryden wind gusts of flexible aircraft in level flight (a) Euler angles versus time, (b) angular velocity versus time, (c) airspeed, angle of attack, and sideslip angle versus time, (d) wingtip accelerations versus time, and (e) wingtip deflections versus time.

locations on the aircraft. In particular, six vertical gusts are applied along the wings, four vertical gusts are applied to the forward and rear horizontal stabilizers, one vertical gust is applied to the center of mass, and one horizontal gust is applied to the vertical stabilizer. The Dryden gust filter assumes an altitude of $1000 \mathrm{ft}$ and produces severe gusts with a wind speed of $75.95 \mathrm{ft} / \mathrm{s}$ at an altitude of $20 \mathrm{ft}$. The Dryden gust filter 

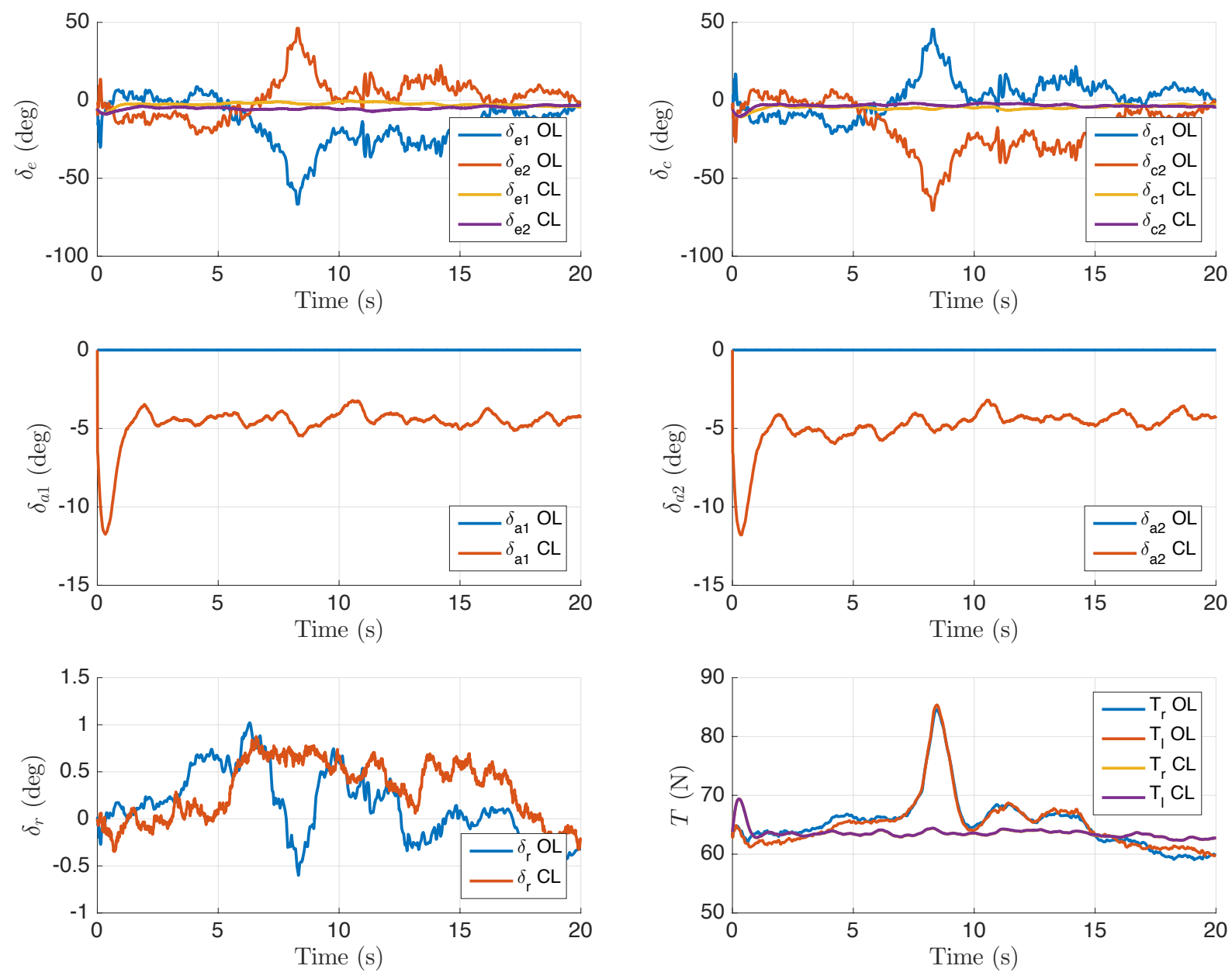

Figure 7. Open-loop (OL) and closed-loop (CL) inputs versus time with Dryden wind gusts of flexible aircraft in level flight. Inputs include right and left elevators, right and left canards, right aileron, left aileron, rudder, and right and left thrust.

used for vertical gusts is given by

$$
G_{w g}(s)=\sigma_{w} \sqrt{\frac{2 L_{w}}{\pi V}} \frac{1+\frac{2 \sqrt{3} L_{w}}{V} s}{\left(1+\frac{2 L_{w}}{V} s\right)^{2}},
$$

where $h=1000 \mathrm{ft}$ is the altitude, $L_{w}=h / 2=500 \mathrm{ft}$ is the turbulence scale length, $W_{20}=75.95 \mathrm{ft} / \mathrm{s}$ is the wind speed at $20 \mathrm{ft}$ altitude, $\sigma_{w}=0.1 W_{20}=7.595$ is the turbulence intensity factor, and $V=65.6 \mathrm{ft} / \mathrm{s}$ is the airspeed.

\section{A. Level-Flight Example}

A desired attitude of $\left(\phi_{d}, \theta_{d}, \psi_{d}\right)=\left(0^{\circ}, 1^{\circ}, 0^{\circ}\right)$ is chosen, along with a desired translational velocity of $\dot{\mathbf{r}}_{a}^{c w, d^{\top}}=\left[\begin{array}{lll}0 & 20 & 0.05\end{array}\right] \mathrm{m} / \mathrm{s}$, and a desired angular velocity of $\boldsymbol{\omega}_{b}^{b a, d^{\top}}=\left[\begin{array}{lll}0 & 0 & 0\end{array}\right] \mathrm{rad} / \mathrm{s}$. The initial conditions are $(\phi(0), \theta(0), \psi(0))=\left(0^{\circ}, 1^{\circ}, 0^{\circ}\right), \dot{\mathbf{r}}_{a}^{c w^{\top}}(0)=\left[\begin{array}{lll}0 & 20 & 0\end{array}\right] \mathrm{m} / \mathrm{s}$, and $\boldsymbol{\omega}_{b}^{b{ }^{\top}}(0)=\left[\begin{array}{lll}0 & 0 & 0\end{array}\right] \mathrm{rad} / \mathrm{s}$. The control gains used by the PFC are $\mathbf{K}_{\mathrm{p}, \mathrm{r}}=\operatorname{diag}\{3,3,3\}, \mathbf{K}_{\mathrm{i}, \mathrm{r}}=\operatorname{diag}\{10,10,10\} 1 / \mathrm{s}, \mathbf{K}_{\mathrm{p}, \omega}=\operatorname{diag}\{90,90,90\} \mathrm{rad} / \mathrm{s}$, $\mathbf{K}_{\mathrm{d}, \omega}=\operatorname{diag}\{40,40,40\}, \mathbf{K}_{\mathrm{i}, \omega}=\operatorname{diag}\{40,40,40\} \mathrm{rad} / \mathrm{s}$, and $k=1 \times 10^{-12} \mathrm{~s} / \mathrm{rad}$. In order to ensure somewhat realistic control inputs, saturation bounds of $\pm 60^{\circ}$ are enforced for all control surface deflections and a lower saturation bound of $0 \mathrm{~N}$ is enforced for the thrust applied by the engines. The linearization of the HALE aircraft used to design DOGLA is performed about the operating point defined by an airspeed of $20 \mathrm{~m} / \mathrm{s}$, an angle of attack of $\alpha=2^{\circ}$, and an attitude of $(\phi, \theta, \psi)=\left(0^{\circ}, 2^{\circ}, 0^{\circ}\right)$. 

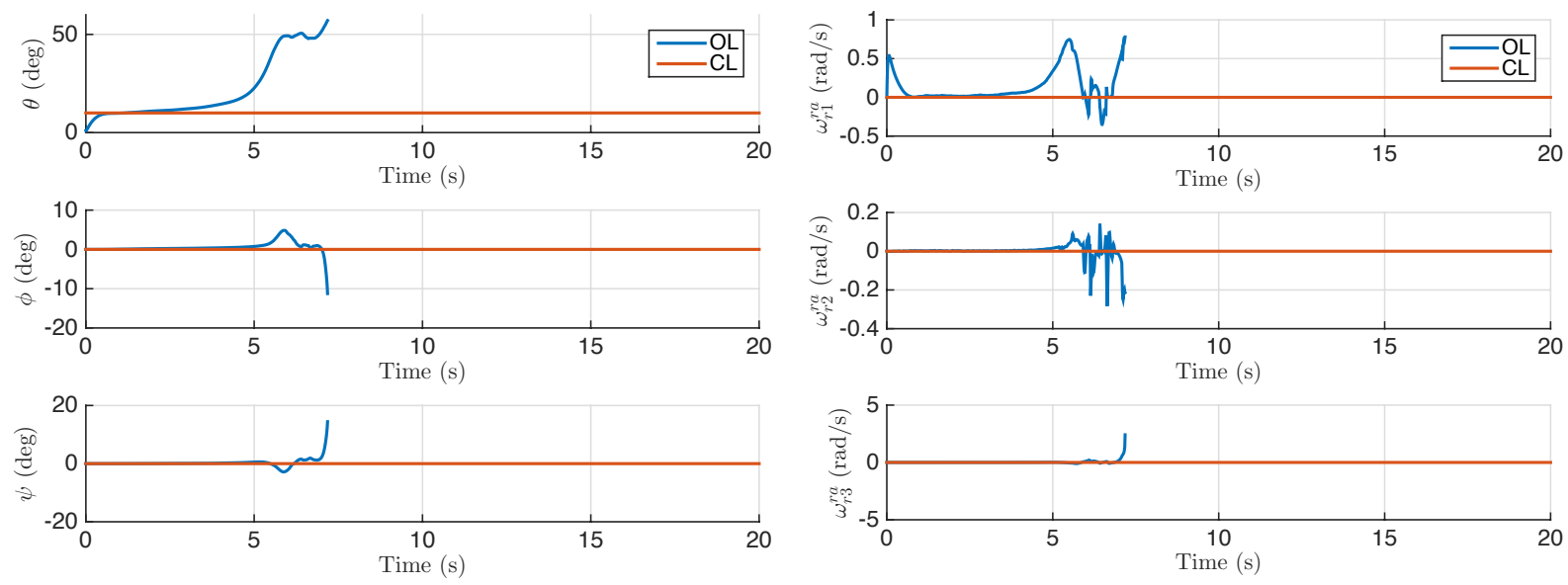

(a)

(b)
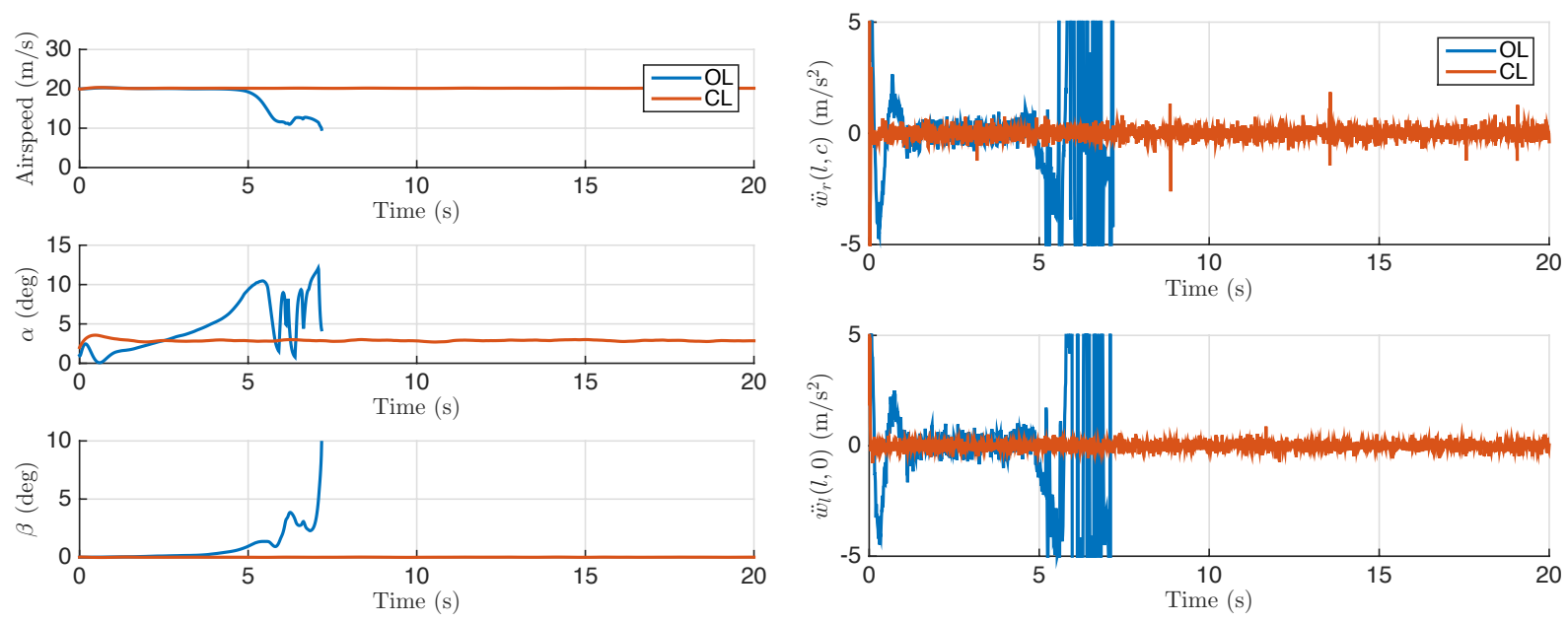

(c)

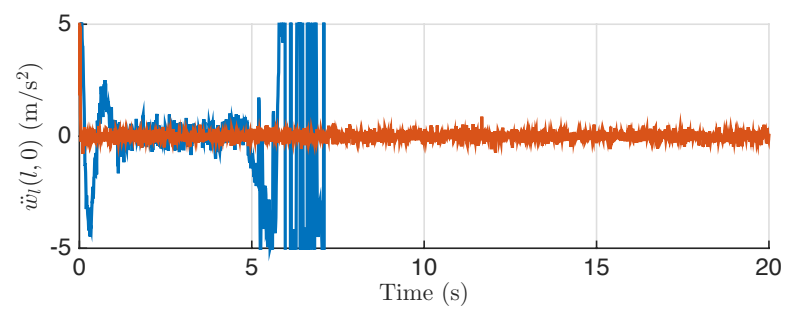

(d)
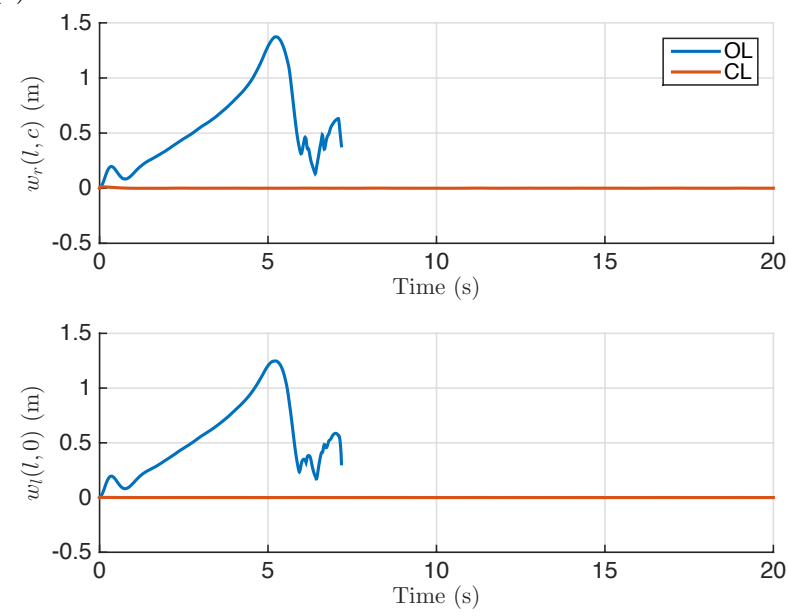

(e)

Figure 8. Open-loop (OL) and closed-loop (CL) responses with Dryden wind gusts of flexible aircraft in ascending flight (a) Euler angles versus time, (b) angular velocity versus time, (c) airspeed, angle of attack, and sideslip angle versus time, (d) wingtip accelerations versus time, and (e) wingtip deflections versus time.

Results of simulations performed with and without DOGLA are presented in Figures 6 and 7, including plots of the aircraft's Euler angles, angular velocity, airspeed, angle of attack, sideslip angle, wingtip accelerations, wingtip deflections, and control inputs versus time. In Figures 6 and 7, the label "OL" in the legend 

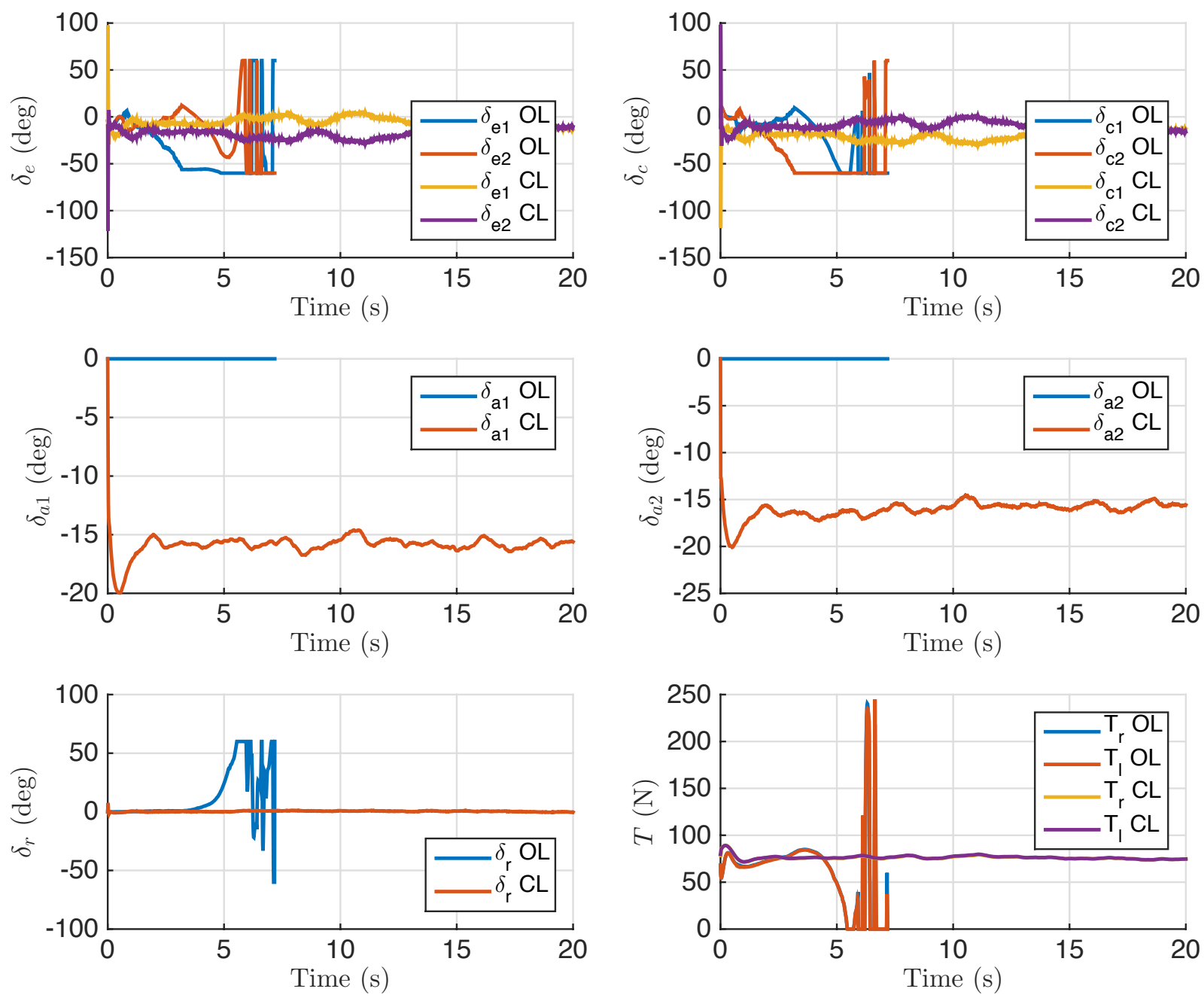

Figure 9. Open-loop (OL) and closed-loop (CL) inputs versus time with Dryden wind gusts of flexible aircraft in ascending flight. Inputs include right and left elevators, right and left canards, right aileron, left aileron, rudder, and right and left thrust.

refers to the response without DOGLA and the label "CL" refers to the response with DOGLA.

\section{B. Ascending-Flight Example}

A desired attitude of $\left(\phi_{d}, \theta_{d}, \psi_{d}\right)=\left(0^{\circ}, 10^{\circ}, 0^{\circ}\right)$ is chosen, along with a desired translational velocity of $\dot{\mathbf{r}}_{a}^{c w, d^{\top}}=\left[\begin{array}{lll}0 & 20 & 2.5\end{array}\right] \mathrm{m} / \mathrm{s}$, and a desired angular velocity of $\boldsymbol{\omega}_{b}^{b a, d^{\top}}=\left[\begin{array}{lll}0 & 0 & 0\end{array}\right] \mathrm{rad} / \mathrm{s}$. The initial conditions are $(\phi(0), \theta(0), \psi(0))=\left(0^{\circ}, 1^{\circ}, 0^{\circ}\right), \dot{\mathbf{r}}_{a}^{c w^{\top}}(0)=\left[\begin{array}{lll}0 & 20 & 0\end{array}\right] \mathrm{m} / \mathrm{s}$, and $\boldsymbol{\omega}_{b}^{b T^{\top}}(0)=\left[\begin{array}{lll}0 & 0 & 0\end{array}\right] \mathrm{rad} / \mathrm{s}$. The control gains used by the PFC are the same as those in the previous level flight case and the same saturation bounds on the control inputs are used. The linearization of the HALE aircraft used to design DOGLA is performed about the same operating point defined by an airspeed of $20 \mathrm{~m} / \mathrm{s}$, an angle of attack of $\alpha=2^{\circ}$, and an attitude of $(\phi, \theta, \psi)=\left(0^{\circ}, 2^{\circ}, 0^{\circ}\right)$.

Simulation results are presented in Figures 8 and 9, including plots of the aircraft's Euler angles, angular velocity, airspeed, angle of attack, sideslip angle, wingtip accelerations, wingtip deflections, and control inputs versus time.

\section{Discussion}

In both the level flight and ascending flight cases, DOGLA significantly improves the performance of the HALE aircraft under severe wind gusts. Without DOGLA, the performance of the aircraft is considerably 
affected by severe wind gusts, even leading to instability in the ascending case. The wingtip DOGLAs make use of the aircraft's ailerons, which serves to damp out vibrations of the flexible wings caused by wind gusts.

The nonlinear simulation results presented in this section highlight the fact that an exact model of the plant is not required when designing DOGLA. Not only is a linearization of the nonlinear model used to design DOGLA in this section, but the operating point used in the linearization differs from the desired operating point in the nonlinear simulation.

The NDI portion of the PFC relies on knowledge of the nonlinear equations of motion of the aircraft, as well as knowledge of the aircraft's flexible coordinates and flexible coordinate rates. In this paper, the true flexible coordinates and flexible coordinate rates are used, whereas in practice, measurements of these quantities are not readily available. This will be remedied in future work by using a combination of nontraditional sensors (e.g., stereo imaging) and an extended Kalman filter (EKF) to estimate the flexible coordinates and flexible coordinate rates using practical measurements.

\section{Conclusion}

A D-MIMO DOGLA was successfully designed and implemented in a simulation of a flexible HALE aircraft. It was shown that DOGLA allows for the performance and stability of the closed-loop system to be virtually unaffected by severe wind gusts in situations where the PFC alone cannot maintain closed-loop stability. DOGLA is able to provide such an improvement in performance and stability by estimating the wind gust disturbance loads and canceling out their effect on the HALE aircraft. This was shown to be effective even when a linearization of the aircraft was used in the design of DOGLA and implemented on the nonlinear model at a desired operating point that differed from the operating point of the linearization.

Future work will examine the stability margins of the closed-loop system with DOGLA and further investigate the design of the low-pass filter $Q(s)$. The flexible coordinates and flexible coordinate rates used in the NDI portion of the PFC will also be estimated using an EKF with practical measurements.

\section{References}

${ }^{1}$ Tilmann, C. P., Flick, P. M., Martin, C. A., and Love, M. H., "High-Altitude Long Endurance Technologies for SensorCraft," RTO AVT-099 Symposium on Novel Vehicle Concepts and Emerging Vehicle Technologies, No. MP-104-P26-1, Brussels, Belgium, April 2003.

${ }^{2}$ Nickol, C. L., Guynn, M. D., Kohout, L. L., and Ozoroski, T. A., "High Altitude Long Endurance UAV Analysis of Alternatives and Technology Development," Tech. Rep. TP-2007-214861, NASA, 2007.

${ }^{3}$ Watts, A. C., Ambrosia, V. G., and Hinkley, E. A., "Unmanned Aircraft Systems in Remote Sensing and Scientific Research," Remote Sensing, Vol. 4, No. 6, 2012, pp. 1671-1692.

${ }^{4}$ Verstraete, D., Coatanea, M., and Hendrick, P., "Preliminary Design of a Joined Wing HALE UAV," 26 ${ }^{\text {th }}$ International Congress of the Aeronautical Sciences, 2008.

${ }^{5}$ Noll, T. E., Brown, J. M., Perez-Davis, M. E., Ishmael, S. D., Tiffany, G. C., and Gaier, M., "Investigation of the Helios Prototype Aircraft Mishap," Tech. rep., NASA, 2004.

${ }^{6}$ Leonard, F., Martini, A., and Abba, G., "Robust Nonlinear Controls of Model-Scale Helicopters Under Lateral and Vertical Wind Gusts," IEEE Transactions on Control Systems Technology, Vol. 20, No. 1, Jan. 2012, pp. 154-163.

${ }^{7}$ Besnard, L., Shtessel, Y. B., and Landrum, B., "Quadrotor Vehicle Control via Sliding Mode Controller Driven by Sliding Model Disturbance Observer," Journal of the Franklin Institute, Vol. 349, No. 2, March 2012, pp. 658-684.

${ }^{8}$ Dillsaver, M. J., Cesnik, C. E. S., and Kolmanovsky, I. V., "Gust Load Alleviation Control for Very Flexible Aircraft," AIAA Atmospheric Flight Mechanics (AFM) Conference, Portland, OR, 2011.

$\rightarrow{ }^{9}$ Dillsaver, M. J., Cesnik, C. E. S., and Kolmanovsky, I. V., "Trajectory Control of Very Flexible Aircraft with Gust Disturbance," AIAA Atmospheric Flight Mechanics (AFM) Conference, Boston, MA, 2013

${ }^{10}$ Caverly, R. J. and Forbes, J. R., "Modeling and Control of a Flexible Kiteplane with Unsteady Aerodynamics," American Control Conference, Boston, MA, July 2016, pp. 4972-4977.

${ }^{11}$ Caverly, R. J. and Forbes, J. R., "Dynamic Modeling, Trajectory Optimization, and Control of a Flexible Kiteplane," IEEE Transactions on Control Systems Technology, 2016, to be published.

12 Sastry, S. S. and Isidori, A., "Adaptive Control of Linearizable Systems," IEEE Transactions on Automatic Control, Vol. 34, No. 11, Nov. 1989, pp. 1123-1131.

${ }^{13}$ Hovakimyan, N., Lavretsky, E., and Sasane, A. J., "Dynamic Inversion for Nonaffine-in-Control Systems via Time-Scale Separation: Part I," Proceedings of the American Control Conference, Portland, OR, June 2005, pp. 3542-3547.

${ }^{14}$ Shearer, C. and Cesnik, C., "Trajectory Control for Very Flexible Aircraft," Journal of Guidance, Control, and Dynamics, Vol. 31, No. 2, 2008, pp. 340-357.

${ }^{15}$ Khalil, H. K., Nonlinear Systems, Prentice Hall, 3rd ed., 2002.

$\checkmark{ }^{16}$ Caverly, R. J., Girard, A. R., Kolmanovsky, I. V., and Forbes, J. R., "Nonlinear Dynamic Inversion of a Flexible Aircraft," IFAC-PapersOnLine, Vol. 49, No. 17, 2016, pp. 338-342, IFAC Symposium on Automatic Control in Aerospace. 
${ }^{17}$ Chaturvedi, N. A., Sanyal, A. K., and McClamroch, N. H., "Rigid-Body Attitude Control," IEEE Control Systems Magazine, Vol. 31, No. 3, 2011, pp. 30-51.

${ }^{18}$ Schrijver, E. and Van Dijk, J., "Disturbance Observers for Rigid Mechanical Systems: Equivalence, Stability, and Design," Journal of Dynamic Systems, Measurements, and Control, Vol. 124, No. 4, 2002, pp. 539-548.

${ }^{19}$ Francis, B. A. and Wonham, W. M., "The Internal Model Principle of Control Theory," Automatica, Vol. 12, No. 5, 1976, pp. 457-465.

${ }^{20}$ Patel, R. V. and Misra, P., "Transmission Zero Assignment in Linear Multivariable Systems - Part II: The General Case," American Control Conference, 1992, pp. 644-648.

${ }^{21}$ Lavretsky, E. and Wise, K. A., Robust and Adaptive Control: With Aerospace Applications, Springer-Verlag, London, UK, 2013.

${ }^{22} \mathrm{Qu}$, Z., Annaswamy, A., and Lavretsky, E., "An Adaptive Controller for Very Flexible Aircraft," AIAA Guidance, Navigation, and Control Conference, Boston, MA, 2013, p. 4854.

${ }^{23} \mathrm{Qu}, \mathrm{Z}$., Wiese, D., Annaswamy, A. M., and Lavretsky, E., "Squaring-Up Method in the Presence of Transmission Zeros," IFAC-PapersOnLine, Vol. 47, No. 3, 2014, pp. 4164 - 4169, 19th IFAC World Congress.

${ }^{24}$ Iwai, Z. and Mizumoto, I., "Realization of Simple Adaptive Control by using Parallel Feedforward Compensator," International Journal of Control, Vol. 59, No. 6, 1994, pp. 1543-1565.

25 Barkana, I., "Parallel Feedforward and Simplified Adaptive Control," International Journal of Adaptive Control, Vol. 1, No. 2, 1987, pp. 95-109.

${ }^{26}$ Caverly, R. J. and Forbes, J. R., "Regional Pole and Zero Placement with Static Output Feedback via the Modified Minimum Gain Lemma," American Control Conference, 2017, submitted for publication.

${ }^{27}$ Caverly, R. J. and Forbes, J. R., "Static Output Feedback Controllers Synthesis with Closed-Loop Minimum Phase Zeros," Automatica, 2016, submitted for publication. 